\title{
Language and Math: What If We Have Two Separate Naming Systems?
}

\author{
Alejandro Martínez ${ }^{1,2}$ \\ 1 Basque Center on Cognition, Brain and Language, 20009 Donostia-San Sebastián, Spain \\ 2 Departamento de Filología Inglesa, Universidad de Valladolid, 47002 Valladolid, Spain; \\ alejandro.martinez.gonzalez@uva.es
}

Received: 17 December 2018; Accepted: 16 August 2019; Published: 29 August 2019

\begin{abstract}
The role of language in numerical processing has traditionally been restricted to counting and exact arithmetic. Nevertheless, the impact that each of a bilinguals' languages may have in core numerical representations has not been questioned until recently. What if the language in which math has been first acquired (LL ${ }^{\text {math }}$ ) had a bigger impact in our math processing? Based on previous studies on language switching we hypothesize that balanced bilinguals would behave like unbalanced bilinguals when switching between the two codes for math. In order to address this question, we measured the brain activity with magneto encephalography (MEG) and source estimation analyses of 12 balanced Basque-Spanish speakers performing a task in which participants were unconscious of the switches between the two codes. The results show an asymmetric switch cost between the two codes for math, and that the brain areas responsible for these switches are similar to those thought to belong to a general task switching mechanism. This implies that the dominances for math and language could run separately from the general language dominance.
\end{abstract}

Keywords: code-switching 1; bilingualism 2; asymmetric switch costs 3; MEG 4; numerical cognition 4

\section{Introduction}

Numbers are one of the pillars in today's society; they can be found in various aspects of life, apart from the obvious counting and arithmetic, such as TV stations, dates, signals, our favorite sports player's number, etc. Numbers are also used to label, rank, order, quantify and measure almost everything. We can calculate the speed of planes, the most complex equations or even simple everyday tasks such as the percentage discount when buying in a shop.

Over the last decades, research into cognitive number processing has made considerable progress and one of the central questions has been how basic numerical knowledge is represented in our minds (Carey 2001; Dehaene et al. 2003; Nieder and Dehaene 2009; Spelke 2000; Whalen et al. 1999). It is believed that humans have an innate system for number representation (Dehaene 1997) also present in infants and animals. This system is considered as an abstract, non-verbal representation of magnitude, and mostly, independent of language. Although the representation of exact magnitudes can be shaped by other numerical information acquired during the early school years, it needs to be learned, since it is not part of the preverbal human core quantity representation. Moreover, magnitude information is encoded or mapped in various symbolic notations (e.g., Arabic, number words) allowing a more precise manipulation of quantity and having an effect on individuals' abilities to compare and represent certain magnitudes (Gilmore et al. 2010; Holloway and Ansari 2008; Moyer and Landauer 1967; Temple and Posner 1998).

There are different notations or formats through which magnitudes can be accessed. Number symbols are generally acquired in at least two forms: Arabic numerals $(1,2,3 \ldots)$ and number words (one, two, three ... ). Contrary to core magnitude knowledge, symbolic numerical codes are culturally 
established (Ansari 2008) and therefore they are learned and retrieved from long-term memory. In turn, the phonological code for the Arabic digits is not specified, mainly because the relation between the visual symbol representing the magnitude and its specific verbal format is arbitrary. The influence that number codes have in magnitude processing has been of special interest over the past years (Cohen Kadosh et al. 2008; Damian 2004; Dehaene and Cohen 1997; Seron and Noel 1995). The general assumption is that number representation can be directly influenced by number codes and that number codes affect the manipulation of number representation (Noël and Seron 1997; Zhang and Norman 1995). Hence, a debate has been established in regard to the existence of one unique numerical representation, independent from the surface code (Dehaene and Cohen 1995) or instead, notation specific representations (Cohen Kadosh et al. 2007). In fact, all the proposed models for the architecture of the numerical system try to provide a comprehensive account of the numerical representation system based on different numerical formats and modalities.

So far, the impact of language in the access to the most basic magnitude representations has been postulated as an ongoing research question in literature. In order to understand the role of language in the core magnitude system, advances in math cognition research have been followed by research on bilingualism (e.g., Bernardo 2001; Salillas and Wicha 2012). Bilingualism is a key to the understanding the bilinguals' preferences for one of the two codes they have for math; and studies about how bilinguals manipulate and switch languages will be reviewed and will also be the focus of this study. The concept of code-switching will be introduced as a way to measure the possible unbalance between number word systems in balanced bilinguals. It also has the objective of knowing the brain bases of switch costs when the number words are manipulated and whether they are similar or different to those used in language and in general switch mechanisms.

\subsection{The Link between Language and Numbers}

Language constitutes the basis of communication and is the most powerful tool not only to share actions or ideas, but also numerical concepts. Although language is the media for transmitting these abstract concepts, the role of language in the evolution of the innate sense of magnitude is not properly defined by any existing theory. Independence between language and math has been challenged by proposals suggesting that the acquisition of number symbols and counting modulates the core numerical magnitude system (Halberda et al. 2008; Piazza et al. 2013).

The current view is that some basic aspects of number cognition development (e.g., arithmetic facts or counting) strongly depend on language (Cappelletti et al. 2001; Delazer et al. 2005; Gelman and Butterworth 2005; Nieder and Dehaene 2009; Piazza 2011; Salillas and Wicha 2012; Spelke and Tsivkin 2001). It is well known that solving simple arithmetic problems involves language processing (Dehaene and Cohen 1995; Dehaene et al. 2003).

The role of language in number development has been the focus of some research (Carey 2004). During the first stages of development, language is obviously part of the process of the acquisition of a more complex numerical knowledge beyond the approximate quantity sense that humans and non-humans share (Feigenson et al. 2004; Gordon 2004; Hodent et al. 2005; Pica et al. 2004). For example, the ability to solve complex calculations is based on our capacity to manage numerical procedures that are mediated by verbal reasoning (i.e., language). A high level of mathematical reasoning can only be reached if an exact quantity representational system is present, and this is possible thanks to language (Carey 2004; Feigenson et al. 2004). The link between language and number appears before any mathematical learning and formal instruction with the acquisition of number words and counting (Dehaene et al. 1999; Feigenson et al. 2004; Gelman and Gallistel 1979; Wynn 1990).

Additionally, studies on cultures with a very limited range of number words to refer to numerical concepts provide us with relevant insights about the relation between language and mathematics (Gordon 2004; Pica et al. 2004). The conclusion which can be drawn from these studies is that the exact arithmetic, contrary to approximate number processing, is thought to be represented in a specific language-coded format. 
In order to better disentangle the relation between language and math, bilingualism offers a good chance to understand this relationship since bilinguals have two different verbal codes to refer to the same numerosity; and since, nowadays, bilingualism is more the rule than the exception, with around half of the world's population are bilingual (Bhatia and Ritchie 2012; Grosjean 2010) and two thirds of the world's children are being raised in a bilingual environment (Crystal 1996), these possible peculiarities for math processing in bilinguals require attention.

The term bilingualism refers to those individuals who have learned more than one linguistic code for oral and written communication (Grosjean 2010). One must bear in mind that bilingualism should not be simplified as a dichotomy of speaking two languages, inside bilingualism we can find a wide range of categories related to fluency and other linguistic domains (Centeno and Obler 2001; Hamers and Blanc 2000; Macnamara 1967). There is a wide range of dimensions to take into account when categorizing bilingualism: Age of acquisition (AoA), percentage of use, context and cultural identity, among others (Xu and Tan 1997; De Houver 2009; Flege et al. 2002; Grosjean 2010; Hazan and Boulakia 1993; Hernandez 2013; Kroll et al. 2012; Valdes et al. 2003). Some of these aspects are relevant for this work, namely the AoA and the relative proficiency.

A language can be acquired very differently across and within societies, going from individuals learning two languages with both languages present in extensive contexts from birth (this would be the case of simultaneous bilinguals in regions such as the Basque Country in Spain), to late learners of a second language (L2) who have less contextual presence in the environment (e.g., learning an L2 without natural immersion). The AoA makes the distinction between these two kinds of bilinguals, the first group being called simultaneous bilinguals, and the second group late learners of an L2 or late bilinguals. The influence of the AoA in the level of competence has been challenged in many studies (Bosch and Sebastián-Gallés 2003; Gandour et al. 2007; Kim et al. 1997; Perani et al. 1998; Perani et al. 2003); some of them supporting the notion of a critical period (DeKeyser 2005; DeKeyser and Larson-Hall 2005; Lenneberg 1967). It is well known that some aspects of a language such as morphology or phonology do not reach a native level when learned in adulthood (Bialystok and Miller 1999; Long 1990; Pinker 1994) and that acquiring an L2 becomes increasingly difficult after puberty (Flege et al. 1995; Johnson and Newport 1989; Weber-Fox and Neville 1996). At the neuroanatomical level, a separate representation networks of bilinguals' L1 and L2 have been related to differences between both languages' age of acquisition (Abutalebi 2008; Chee et al. 2001; García-Pentón et al. 2014; Perani et al. 1998).

Bilingual research on math cognition has demonstrated that bilinguals feel more comfortable and perform better on the language in which they have learnt arithmetic in school (Marsh and Maki 1976) and show worse performance when numerical problems were posed in their weaker language or L2 (Frenck-Mestre and Vaid 1993; Morales et al. 1985).

The consequences of bilingualism in the development of numerical skills have attracted interest over the last decades and have taken into account critical factors such as AoA, the language of instruction in early learning of math, and language proficiency. These studies have also permitted a deep look at the role played by language in our math system. Based on current evidence, it is assumed that mathematical development in bilinguals normally involves one of the two languages preferentially (Bernardo 2001; Grabner et al. 2012; Martinez-Lincoln et al. 2015; Salillas et al. 2015; Salillas and Wicha 2012). It is also well-known that bilinguals often translate or switch languages when carrying out simple arithmetic facts or for mathematical thinking in general (Moschkovich 2007). This preference for a language for number processing could be the language in which math has been studied (Bernardo 2001; Clarkson and Galbraith 1992; Frenck-Mestre and Vaid 1993; Geary et al. 1993; Kolers 1968).

The influence of learning experiences in setting a preferred verbal code for arithmetic was vaguely contemplated in the Encoding-Complex Model (Campbell 1994; Campbell 2005; Campbell and Clark 1988; Campbell and Epp 2004). The model claims that the bilingual arithmetic memory system keeps a relatively strong link with the language used for learning and arithmetic fact retrieval. The connection between one of the languages and the arithmetic memory networks, as well as the analogue magnitude 
code, will depend on the prior experience in direct retrieval of numerical information and not on the proficiency of the language (see Figure 1).

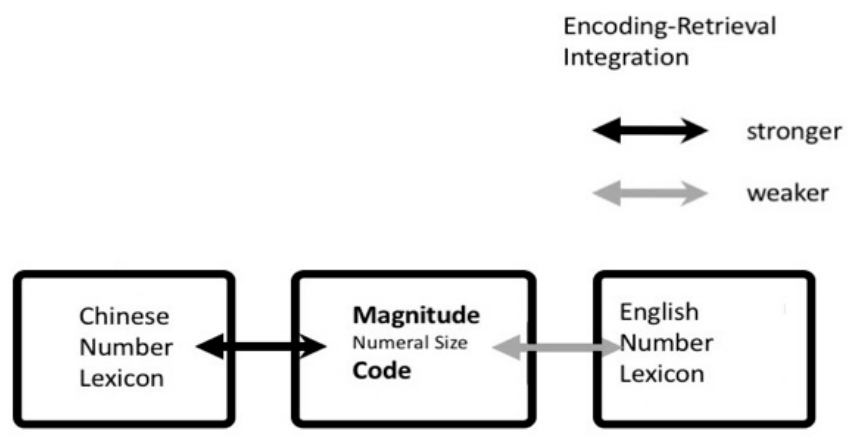

Figure 1. Illustration of a simplification of the Encoding-Complex hypothesis by Chinese-English bilinguals (Campbell and Epp 2004). The arrows have two different colors, according to the strength of the integrations. Grey arrows illustrate weak integration of the interfacing processing, black arrows represent strong integration. Therefore, the Chinese Number Lexicon (acquired at school) has a stronger connection to the Magnitude code than the English Number Lexicon.

The latest research on bilingual math representations has shown that the bilingual numerical system could include linguistic traces (Salillas et al. 2015; Salillas and Carreiras 2014). Hence, a preference for one of the languages not only in exact arithmetic but also in the fundamental number representations has been suggested. The present study directly investigates this possible lexical unbalance for math: That is, whether there is an unbalanced dominance for the two bilingual numerical lexicons that runs independently of the relative proficiency in general linguistic representations.

A critical factor should be how the learning process of numerical knowledge is influenced by language and how it determines the brain organization and functioning of the numerical system in bilinguals. The neuronal correlates in the process of learning exact arithmetic have been widely explored (Dehaene and Cohen 1997; Lemer et al. 2003; Delazer and Benke 1997; Venkatraman et al. 2006). The general finding is a difference in the language networks (AG, left inferior frontal gyrus) when comparing the exact and arithmetic mathematical processing.

In addition to the influence of language in exact arithmetic, the linguistic traces in the quantity code as a result of early learning processes of numerical verbal symbols has also been studied using ERPs. Salillas and Carreiras (2014) showed that a different ERP pattern was associated to the Basque wording system (base 20) as a function of the LL ${ }^{\text {math }}$, since very proficient Basque bilinguals whose LL $^{\text {math }}$ was Spanish did not show this pattern for the Basque wording system. This suggests that verbal signatures in the core magnitude representation system are due to early learning. These results provide information about when number words attach to quantity in the balanced bilingual participants, during early math learning.

To sum up, the results shown in the previous studies suggest that language plays an important role in exact arithmetic and it could influence the core numerical representation. Thus, bilingualism could imply a specific case for math. The fact that bilinguals manage two verbal codes for the same numerosity sets the question of whether these codes are equally represented or, on the contrary, imply an imbalance with consequences for math processing. According to the proposed relevance of early learning and a preferential link between one of the languages and core number representations, an essential question arises: Are the two number words systems in a bilingual equally represented? In other words, a proficient bilingual may have an equally strong representation for the word 'sea' and the word 'mar'. However, the same bilingual might present an unbalanced representation for number words, 'one' versus 'uno'. As we will see, a straightforward way of measuring such an unbalance is through the study of language switching and the relative costs implied in the switching between the 
two number word systems. Language switching has been profusely studied in bilingual language cognition, as exposed below.

\subsection{Bilingualism and Code-Switching}

One commonality to all bilinguals is the ability to switch between languages. When bilinguals perform this switch, there is always an effort. This effort is known as switch cost (Costa and Santesteban 2004; Jackson et al. 2001; Meuter and Allport 1999; Palmer et al. 2010). Switch trials elicit longer reaction times and differential ERP effects (Costa and Santesteban 2004; Macizo et al. 2012; Meuter and Allport 1999; Palmer et al. 2010). Balanced bilinguals switch between L1 and L2 indistinctly with the same effort; this is known as a symmetric switch cost language: Switches are similar in both directions (L2 to L1 and L1 to L2). However, unbalanced bilinguals show an asymmetry in the switch: It always takes more effort to switch in one direction than in the other; this is known as an asymmetric switch cost (Costa and Santesteban 2004; Duñabeitia et al. 2010; Meuter and Allport 1999). In Meuter and Allport (1999), participants named items in their L1 or L2. Results showed that bilinguals named items faster in their L1 than in their L2 in non-switch trials. However, in switch trials, subjects named items more slowly in their L1 than in their L2. Based on the Inhibitory Control (IC) model by Green (1998), the authors argued that this additional time is needed mainly because the more dominant language (L1) requires more inhibition during L2 naming trials, since inhibition is carried on to the next trial, a switch from L2 to L1 needs to overcome this inhibition, hence making this switch harder than a L1 to L2 switch. Importantly, a different switch pattern seems to appear for balanced bilinguals. Costa and Santesteban (2004) contrasted language switching performance between balanced and unbalanced bilinguals and only the unbalanced group showed asymmetric switch costs. What determines the asymmetry or symmetry according to these studies is the level of proficiency that ultimate modifies the mechanisms of inhibition or selection over the two lexicons in production tasks (Costa and Santesteban 2004) or the automaticity of the activations for words in the two languages during comprehension (Duñabeitia et al. 2010).

Asymmetric switch costs have frequently been found in event-related potentials (ERPs) studies in at least two different components: The N2 and the N400; these are negative-going ERP waves that peak 200-350 ms and 350-500 ms post-stimulus, respectively (Chauncey et al. 2008; Jackson et al. 2004; Jackson et al. 2001; Verhoef et al. 2009). Dissociation between these components is also reported for each switch direction, suggesting also neurofunctional differences: Chauncey et al. (2008) found a switching effect in the N400 when switching in the L2-L1 direction, and in the N250 in the L1-L2 direction. Additionally, Duñabeitia et al. (2010) performed a similar study with early bilinguals who showed a switch effect in the N2 component for both directions of the switch (i.e., L2 to L1 and L1 to L2) and found no asymmetric switch, concluding that the asymmetry observed by Chauncey et al. (2008) was language-dominance related. Overall, behavioral and electrophysiological studies converge in showing that relative proficiency between languages modulates switch costs, and switch asymmetry appears in unbalanced bilinguals. Therefore, an asymmetry between switch directions can be taken as an index of unbalance in the representational strength for each verbal code.

This aspect is of special relevance for this paper since we will observe the symmetry in switches between number words as an index of the balance or unbalance between the two number word systems, positing that even in overall balanced bilinguals an unbalance should be shown for number words. In sum, the revised studies demonstrate that switching languages in bilinguals requires an extra effort, and that this effort is asymmetric in unbalanced bilinguals since one of the directions of the switch shows higher activation or bigger amplitude in the ERP components. These switch costs could be due to a general control mechanism.

One crucial question is whether these switch costs are dependent on the dominant language (L1), or on the contrary, bilingualism means an independent dominance pattern for mathematical representations. This question has not been directly addressed yet. Some studies have addressed the representation of arithmetic facts in bilinguals (Bernardo 2001; Salillas and Wicha 2012; Vaid and Menon 2000), focusing on the role of early learning in arithmetic representations. More recently, we have 
extended the question further to the impact of each of the languages in core numerical representations: In Salillas and Carreiras (2014) it was suggested that one of the languages might enter into the core magnitude representation. This language would correspond to the language used for learning math during early education (LL ${ }^{\text {math }}$ ). Thus, early math learning would impact not only arithmetic, but also essential numerical knowledge. However, a direct test of the relative dominance between the numerical lexicons in bilinguals is missing. A classical way to study such dominance pattern is through the observation of the cost of switching between the two verbal codes.

To test the impact of early math learning in the relative strength of the two numeric lexicons, we will distinguish between the LL ${ }^{\text {math }}$ and the other language (hereafter OL) as what determines their relative dominance. Such distinction was not considered previously, albeit using non-numerical tasks (Meuter and Allport 1999). Here, we will sustain that while our bilinguals will be L1-L2 balanced bilinguals in terms of proficiency and general language use; early learning experience (i.e., LL ${ }^{\text {math }}$ ) is what will determine a higher resting activation for the number words in one of the languages based on previous findings (Salillas and Carreiras 2014; Salillas and Wicha 2012). Thus, if what determines the relative representational strength of the two numerical lexicons is just overall language proficiency (L1-L2), balanced bilinguals should show symmetric switch costs even when considering the $L^{\text {math }}$-OL distinction for analysis, because both languages would have equivalent dominance based on general language functioning. However, if a larger switch cost appears in the OL to LL ${ }^{\text {math }}$ transition this would index a higher resting activation in $\mathrm{LL}^{\text {math }}$.

In the present study, we will observe for the first time the unbalance for numerical wording systems in balanced bilinguals. It has already been shown that bilinguals have a preference for one of their two codes in arithmetic representations (Martinez-Lincoln et al. 2015; Salillas and Wicha 2012; Spelke and Tsivkin 2001) and more recently it has been shown that LL math might be the language of preference for accessing magnitude (Salillas et al. 2015; Salillas and Carreiras 2014). This preference is proposed to take place during early math learning. At the same time this preference will show an unbalance in the switch between the codes for math and consequently, balanced bilinguals will be more "proficient" in their LL ${ }^{\text {math }}$. This effect should manifest as an asymmetric switch cost when switching between their two codes for math.

\subsection{Bilingual Language Control}

Though one may come across different ideas of how bilinguals process and switch languages, there are two main views on the consequences of frequent switching between languages in bilinguals. There are authors that propose that bilinguals have advantages over monolinguals in attentional resources, memory skills and executive control mechanisms. In other words, speaking several languages can lead to benefits that go beyond the realm of language, impacting on global cognitive functioning (Bialystok et al. 2012). These advantages are somehow boosted by bilingualism due to the constant need of bilinguals to inhibit one of their languages while they use the other. This language inhibition is believed to be a part of a greater general mechanism of inhibition and since language inhibition is used every day it helps to improve the general inhibition mechanism (Abutalebi et al. 2012; Craik and Bialystok 2006; Garbin et al. 2010). Another view on this matter is that the mechanism of inhibition used in languages belongs solely to the language system and therefore is not part of any general mechanism (Abutalebi et al. 2008; Calabria et al. 2012).

Bilingual language processing and control has been investigated in numerous studies (Abutalebi et al. 2008; Abutalebi and Green 2007; Chee et al. 1999; De Bleser et al. 2003; Hernandez et al. 2001; Hernandez et al. 2000; Perani et al. 2003; Swainson et al. 2003; Wang et al. 2007; Yetkin et al. 1996). A common finding in these studies is a significant difference in activation in the brain regions involved in language switching. For example, Hernandez et al. (2001) studied switches between languages in a group of early Spanish-English speakers. Switch conditions showed increased activity the left dorsolateral prefrontal cortex relative to the non-switching condition. Chee et al. (2003) reported similar results. Additionally, Rodriguez-Fornells et al. (2002) looked into the neural correlates of 
language selection in early Catalan-Spanish bilinguals. They wanted to find out how the non-target language is inhibited by bilinguals. They addressed this question by combining ERPs and fMRI. When comparing the results to a Spanish monolingual control group authors found that only bilinguals showed activation of a left anterior prefrontal region (Brodmann areas 45 and 9).

Another study examining language switching was done by Jackson et al. (2001). Participants had to name digits in the target language cued by the color of the digit. The N2 component recorded over the left frontocentral region and typically associated with response inhibition, was much more negative for switch conditions (as compared to non-switch conditions) when individuals switched from naming in L1 (the habitual language) to naming in L2. Such data are consistent with the notion that the more dominant language requires more active suppression.

Additionally, Jackson et al. (2001) examined the effects of switching on activity in the parietal cortices and found that switching induced an increase over the parietal cortices in the late positive component (LPC) associated with increased demands on response selection as in the Stroop interference. The authors related these results with the idea that language switching increased frontal and parietal activity consistent with the requirement to inhibit ongoing activity and select a relevant response in the face of competition.

In sum, the revised studies demonstrate that switching languages in bilinguals requires an extra effort, and that this effort is asymmetric in unbalanced bilinguals since one of the directions of the switch shows higher activation or bigger amplitude in the ERP components. These switch costs could be due to a general control mechanism. These facts establish the ground on which most of this experiment relies, namely, that with regard to number words, this unbalance will be set by LL math and not by general proficiency. Studies examining language switching at the neuronal level show that the regions implicated in these switches are usually frontal areas as the dorsolateral prefrontal cortex (DLPFC) (Hernandez et al. 2001; Hernandez et al. 2000; Rodriguez-Fornells et al. 2006; Wang et al. 2007) or left anterior prefrontal regions including pars triangularis (Brodmann areas 45 and 9). Rodriguez-Rodriguez-Fornells et al. (2002) reported language-switching involving the left ACC as well (Abutalebi et al. 2008; Crinion et al. 2006; Van Heuven et al. 2008; Wang et al. 2007). In this experiment, we measured magnetic brain activity during a masked priming paradigm. The use of Magnetoencephalography (MEG) allows to estimate where in the cortex the switch-costs are originated, while preserving the same good temporal resolution provided by EEG.

We hypothesize that in L1/L2 balanced bilinguals, the determinant factor for a preferential code for math will be early learning experience (i.e., $L L^{\text {math }}$ ). In order to sort out this preference we will distinguish between the two codes for math: The language for learning math (LL ${ }^{\text {math }}$ ) and the other language (OL) as the determinant factors of this relative dominance. The novelty of this experiment is that this $\mathrm{LL}^{\text {math }}$-OL distinction has not been previously considered in numerical tasks as the dichotomy L1/L2 is always considered. Based on previous ERP switch studies (Chauncey et al. 2008; Jackson et al. 2001) we predict that switching between LL ${ }^{\text {math }}$ and OL will generate asymmetric N400 switch costs. A larger switch cost should appear in the OL to LL ${ }^{\text {math }}$ transition whereas a lower switch cost should be found in the other direction. Additionally, we hypothesize that the neural networks responsible for the mechanisms underlying the switches in these two codes for math and if they are the same as the ones used in general language switching.

\section{Materials and Methods}

\subsection{Participants}

Participants from the area of Gipuzkoa in the western part of the Basque Country in Spain. In the Basque Country, specially in the area of Gipuzkoa, Basque and Spanish share the same status and both languages are spoken indifferently. Formal education in the Basque Country can be received in Spanish, Basque or both languages, but math is always taught in one language or another. 
The participants who enrolled in the study had to be proficient in both languages (see Language assessment below) and had to report which of the languages was their LL ${ }^{\text {math }}$ (the first language used for math learning in school, in which language they learnt arithmetic and which language they used for counting and calculation) and whether they felt comfortable counting and doing basic mathematical operations in each language. They also had to have contact with both languages before the age of three, speak both languages at home and the amount of daily use should be at least $40 \%$ for each language.

Twelve participants matched the selection criteria. They were twelve healthy right-handed Spanish - Basque bilinguals (six females and six males), mean age $=26$, range $=21-30$ years. All participants were exposed to Basque and Spanish before the age of three. Of the 12 participants, six learned math in Basque and the other six learned it in Spanish at school The study was carried out in the Basque Center on Cognition Brain and Language (BCBL) and was approved its institutional review board. All subjects gave their written informed consent for inclusion before they took part in the study. The study was conducted in accordance with the Declaration of Helsinki.

\subsection{Language Assessment}

Language proficiency was assessed with the same three different measures in both languages (Basque and Spanish) which consisted of: (1) The Boston Naming Test (Kaplan et al. 1983)); (2) an oral interview performed by an expert and native speaker of both languages. The interview assessed not only the general vocabulary knowledge, but also general fluency and knowledge of the language, i.e., how participants formulated sentences correctly in both languages, verb conjugations, ability to get their messages through, etc. Scoring in the interview went from zero to five, being zero the lowest score (lack of the knowledge being tested) to five (complete mastery of the language) and (three) participants also reported the percentage of daily use of each language (see Table 1).

Table 1. Scores in the different language tests (Experiment 1) for both: Boston Naming Test (BNT): Mean scores in BNT, (Kaplan et al. 1983). \% daily use: Mean percentage of use reported by participants. Interview: Mean score in the interview session, scores ranged from one to five. \% Input refers to the average amount of time exposed to each language (reading, writing, speaking and listening) by the participants in each language.

\begin{tabular}{ccccc}
\hline & \multicolumn{2}{c}{ LL $^{\text {math }}=$ Spanish } & \multicolumn{2}{c}{ LL $^{\text {math }}=$ Basque } \\
\hline & Spanish & Basque & Spanish & Basque \\
\hline BNT & 54 & 49 & 54 & 55 \\
\% Daily use & 57 & 43 & 60 & 40 \\
Interview & 5 & 5 & 5 & 5 \\
\% Input & 51 & 49 & 55 & 45 \\
\hline
\end{tabular}

\subsection{Stimuli and Procedure}

Stimuli consisted of numbers in their verbal form. The numbers ranged between one and eight, and excluding six since it is a cognate $\left(\operatorname{seis}_{\mathrm{SPA}}-s e i_{\mathrm{EU}}-s i x_{\mathrm{EN}}\right)$ and nine since it is substantially longer in Basque than in Spanish (nueve $\mathrm{SPA}_{\mathrm{SA}}-$ bederatzi $_{\mathrm{EU}}$ ). Stimuli could be presented in two formats: In Spanish (e.g., cinco 'five'), or in Basque (e.g., bost 'five'). There was no phonological overlap for the numbers between languages (see Table 2 below). Numbers from 10 onwards were excluded in the study, this was done to avoid potential confounding effects since Spanish and Basque have different systems for naming two-digit numbers (see Salillas et al. 2015). Additionally, numerical distance was equated across all the trials, that is, in all the critical trials prime and targets were different with a numerical distance of one or three; and these two numerical distances appeared the same number of times during the task. 
Table 2. Written forms of the numbers in Spanish, Basque and the pseudo-words created for each language. Their corresponding digits are also presented. Numbers six was excluded from the study due to its similarity in Basque and Spanish and nine was excluded from the analyses due to the fact that its difference in length with the rest of the numbers helped to recognize it faster.

\begin{tabular}{cccccccccc}
\hline Number & $\mathbf{1}$ & $\mathbf{2}$ & $\mathbf{3}$ & $\mathbf{4}$ & $\mathbf{5}$ & $\mathbf{6}$ & $\mathbf{7}$ & $\mathbf{8}$ & $\mathbf{9}$ \\
\hline Spanish & uno & dos & tres & cuatro & cinco & seis & siete & ocho & nueve \\
Basque & $b a t$ & $b i$ & hiru & Lau & bost & sei & zazpi & zortzi & bederatzi \\
$\begin{array}{c}\text { Pseudo-word } \\
\text { Spanish }\end{array}$ & $i b o$ & fos & fres & cungro & cengo & - & hieve & etro & hieve \\
$\begin{array}{c}\text { Pseudo-word } \\
\text { Basque }\end{array}$ & zat & bo & seru & Jau & botz & - & zelpi & lortsi & bemekatxe \\
\hline
\end{tabular}

Participants were asked to perform a lexical decision task; in order to avoid participant perception of what the real task was about they were told to classify the items appearing on the screen as "real" words or pseudo-words. All "real" words were numbers whereas pseudo-words were words derived from the numbers used as stimuli. In order to create these pseudo words, letters were changed in a range from two to four letters (e.g., tres-fres), but none of these trials were included in the analysis. The reason for including a lexical decision task instead of a specific numerical task, is that we wanted a task in which access to magnitude was indirect, as it has been previously reported that in specific numeral tasks there is a preference for the LL ${ }^{\text {math }}$ (Salillas and Martínez 2018).

The masked priming sequence began with a forward mask composed of hash-marks (\#\#\#\#\#\#) displayed during $500 \mathrm{~ms}$. The forward mask was replaced at the same location on the screen by a lower case prime item for $40 \mathrm{~ms}$. The prime was immediately replaced by the target in uppercase letters that remained on the screen for $1000 \mathrm{~ms}$. All target words were followed by an interrogation (?) to indicate when the participants should respond (see Figure 2 for a schema of the trials in the task). A total of 384 trials were created, one half (192) were Basque trials, and the other half (192) were Spanish trials. These trials were then divided into switch trials (96 Basque-Spanish switch trials and 96 Spanish-Basque switch trials); and non-switch trials (96 Spanish-Spanish non-switch trials and 96 Basque-Basque non-switch trials). Additionally, a total of 640 distractors were included; these distractors were the pseudo-words mentioned above.

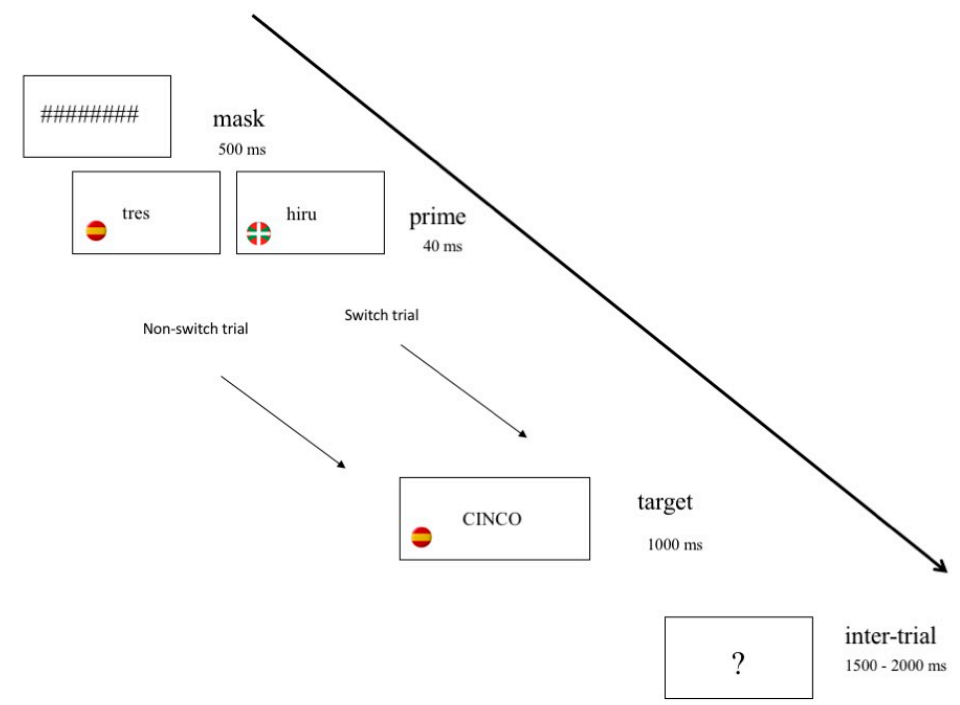

Figure 2. The design of this experiment was masked priming. Non-switch trials: The target was in the same language as the prime (e.g., tres-CINCO). Switch trials were Spanish-Spanish or Basque-Basque. Switch trials: The target was in a different language (e.g., hiru-CINCO). Non-switch trials were Spanish-Basque switches and Basque-Spanish switches. 


\subsection{MEG Analyses}

Data was acquired in a magnetically shielded room using a whole-scalp MEG system (Elekta-Neuromag, Helsinki, Finland) installed at the BCBL. The system is equipped with 102 sensor triplets (each comprising a magnetometer and two orthogonal planar gradiometers) distributed around the head of the participant. We continuously monitored how the head position inside the helmet was by using four head position indicator (HPI) coils. A 3D digitizer (Fastrak Polhemus, Colchester, VA, USA) was used to define the location of each coil relative to the anatomical fiducials (nasion, left and right preauricular points). This procedure is of extreme importance for head movement compensation during the data recording session. Digitalization of the fiducials plus around 100 additional points evenly distributed over the scalp of the participant were used during subsequent data analysis to spatially align the MEG sensor coordinates with T1-weighted MPRAGE magnetic resonance brain images acquired on a 3T magnetic resonance imaging (MRI) scan (Siemens Medical System, Erlangen, Germany). A continuous bandpass filter at $0.01-330 \mathrm{~Hz}$ and a sampling rate of $1 \mathrm{kHz}$ was used for the acquisition of the MEG recordings. Eye-movements were monitored with two pairs of electrodes in a bipolar montage placed on the external chanti of each eye (horizontal electrooculography (EOG) and above and below right eye (vertical EOG). Source reconstruction in the cortical surface and volumetric segmentation was reduced to 15,000 vertices in order to simplify analyses, and performed with the Freesurfer image analysis suite, which is documented and freely available for download online (http://surfer.nmr.mgh.harvard.edu/). Briefly, this processing corrects for motion and, when having multiple volumetric T1 weighted images, performs an average, removes non-brain tissue by using a hybrid watershed/surface deformation procedure automated Talairach transformation, segments the subcortical white matter and deep gray matter volumetric structures (including hippocampus, amygdala, caudate, putamen, ventricles). Freesurfer morphometric procedures have been demonstrated to show good test-retest reliability across scanner manufacturers and across field strengths (Han et al. 2006; Reuter et al. 2012).

\subsubsection{Data Pre-Processing}

To remove external magnetic noise from the MEG recordings, data were preprocessed off-line using the temporal Signal-Space-Separation method (Taulu et al. 2005) implemented in Maxfilter 2.1 (Elekta-Neuromag). MEG data were also corrected for head movements, and bad channels were substituted using interpolation algorithms implemented in the software. Subsequent analyses and heartbeat and EOG artifacts and data analysis was performed with Brainstorm (Tadel et al. 2011), which is documented and freely available for download online under the GNU general public license (http://neuroimage.usc.edu/brainstorm).

\subsubsection{Source Estimation Analyses (MNE)}

The method used to estimate the sources distributed in the cortex was MNE (Gramfort et al. 2014) based on all the sensors for each participant/condition average time course. We used the T1-weighted MRI scans for each individual. Analyses were performed individually using the standard weighted minimum norm estimate (wMNE) generating a source model for the 15,000 vertices. Before the wMNE source reconstruction was calculated, the covariance matrix required for computing the wMNE source reconstruction was obtained based on the data during a $100 \mathrm{~ms}$ baseline period. An overlapping spheres method was used to estimate the forward model. Estimated source activations were standardized using a Z-score transformation with respect to the average and standard deviation of the source activity during the $100 \mathrm{~ms}$ baseline period. The Z-score source space activity was then projected to a template (ICBM152 anatomy) for all subjects/condition and averaged for visualization. Relevant latency bands (300-500 ms) from the event related field (ERF) analyses (see below) were averaged across time in the Z-score source files and exported for each condition/participant into 3D activation maps for statistical 
analyses at the group level. These analyses consisted of $n=12$ F-tests (switch $\neq$ non-switch) using SPM8 with an uncorrected threshold of $p<0.001$.

\subsubsection{ERF Analyses}

Sensor clusters and latency bands were identified from previous studies and from Experiments 1 and 2 (Blanco-Elorrieta and Pylkkänen 2016; Chauncey et al. 2008; Christoffels et al. 2007; Duñabeitia et al. 2010; Jackson et al. 2001). MEG sensors were regrouped into a total of eight clusters, that is four clusters by hemisphere (temporal left, temporal right, paracentral left, paracentral right, parietal left, parietal right, frontal left, frontal right). Based on Experiment 1 and 2 results, a window between $300 \mathrm{~ms}$ and $500 \mathrm{~ms}$ was considered for the analyses. This time window was divided into $50 \mathrm{~ms}$ smaller windows to better capture the effects (similar to Experiments 1 and 2). T-tests were performed in each time window comparing mean amplitudes of relevant latency bands in each cluster. Again, the contrast LL ${ }^{\text {math }}-\mathrm{OL}$ was considered from participants whose $\mathrm{LL}^{\text {math }}$ was Basque (conditions LL ${ }^{\text {math }}$ LL $^{\text {math }}$, OL-LL ${ }^{\text {math }}$, OL-OL, LL ${ }^{\text {math }}$-OL, i.e., Basque-Basque, Spanish-Basque, Spanish-Spanish, Basque-Spanish, respectively), and for participants whose LL ${ }^{\text {math }}$ was Spanish (conditions LL ${ }^{\text {math }}$ LL $^{\text {math }}$, OL-LL ${ }^{\text {math }}$, OL-OL, LL ${ }^{\text {math }-O L, ~ i . e ., ~ S p a n i s h-S p a n i s h, ~ B a s q u e-S p a n i s h, ~}$ Basque-Basque, Spanish-Basque, respectively). The four conditions were collapsed between languages for analysis, providing exactly the same stimuli between conditions. Contrasts for switch costs entailed the contrast between the switch condition and the non-switch condition for each of the directions (to $L L^{\text {math }}$ : OL-LL ${ }^{\text {math }}$ versus $L^{\text {math }}{ }^{-L L^{\text {math }}}$ and to OL: $L^{\text {math }}$-OL versus OL-OL).

\section{Results}

\subsection{Behavioral Data}

Behavioral data showed significant results. At first sight, reaction times showed that the mean for the switch conditions had was higher than the non-switch condition. The percentage of errors was minimal $(<1.96 \%$, see Table 3$)$ and the data analyzed are the reaction times of the correct responses given by the participants. When comparing the switch versus non-switch conditions in each code the $t$-tests revealed a significant difference for the $\mathrm{LL}^{\text {math }}-\mathrm{LL}^{\text {math }}(\mathrm{M}=448, \mathrm{SE}=15), \mathrm{OL}-\mathrm{LL}^{\text {math }}(\mathrm{M}=498$, $\mathrm{SE}=16)$, comparison $\mathrm{t}(11)=2.156, p=0.038$. However, this effect was not significant in the OL-OL $(\mathrm{M}=535, \mathrm{SE}=23), \mathrm{LL}^{\text {math }}-\mathrm{OL}(\mathrm{M}=509, \mathrm{SE}=22)$ comparison, $\mathrm{t}(11)=1.087, p=0.287$.

\subsection{Source Space}

In order to observe the evolution in the brain sources the original 300-500 ms window was split into four smaller windows (300-350, 350-400, 400-450, 450-500). The first time-window that showed a switch effect was the 400-450 showing activation in the left middle frontal gyrus and anterior cingulate gyrus (Brodmann Area 32). In the 450-500 ms time window similar effects were revealed in the dorsolateral prefrontal cortex (DLPFC) (see statistical parametric maps in Figure 3 and exact peak coordinates in Table 4).

\subsection{ERFS}

A visual analysis of the ERF data showed that a component peaking between $300 \mathrm{~ms}$ and $500 \mathrm{~ms}$ was more negative for the switch conditions than for the non-switch conditions (see Figure 3). This difference started at $400 \mathrm{~ms}$ and ended at $500 \mathrm{~ms}$ as revealed by a consecutive $50 \mathrm{~ms}$ time windows analysis (i.e., $400-450 \mathrm{~ms}$ and $450-500 \mathrm{~ms}$ ) contrasting all switch versus non-switch trials. The t-tests in each region showed a switch effect only for the OL-LL ${ }^{\text {math }}$ vs. LL ${ }^{\text {math }}-L_{L}{ }^{\text {math }}$ switch in the $400-450 \mathrm{~ms}$ time window in the left frontal area $t=-2.289, p=0.043$ (see Figure 4 ) and in the 450-500 ms the left temporal areas showed an effect of switch $t=2.487, p=0.030$ (see Figure 4). However, the $t$-test in the $\mathrm{LL}^{\text {math }}$-OL switch direction did not show any significant results in any region. 
Table 3. Percentages of correct, incorrect and missing answers by condition and participant in \%.

\begin{tabular}{|c|c|c|c|c|c|c|c|c|c|c|c|c|}
\hline \multirow[b]{2}{*}{ Participant } & \multicolumn{4}{|c|}{ Correct } & \multicolumn{4}{|c|}{ Incorrect } & \multicolumn{4}{|c|}{ Miss } \\
\hline & $\mathbf{L L}^{\text {math }} \mathbf{L L}^{\text {math }}$ & $\mathbf{L L}^{\text {math }}-\mathrm{OL}$ & OL-LL ${ }^{\text {math }}$ & OL-OL & $L^{\text {math }}$-LL ${ }^{\text {math }}$ & $L^{\text {math }}{ }_{-O L}$ & OL-LL ${ }^{\text {math }}$ & OL-OL & $\mathbf{L L}^{\text {math }}-\mathbf{L L}^{\text {math }}$ & $\mathbf{L L}^{\text {math }}-\mathrm{OL}$ & OL-LL ${ }^{\text {math }}$ & OL-OL \\
\hline 1 & 96.88 & 97.92 & 98.96 & 97.92 & 3.13 & 2.08 & 1.04 & 2.08 & 0.00 & 0.00 & 0.00 & 0.00 \\
\hline 2 & 95.83 & 93.75 & 95.83 & 100.00 & 4.17 & 4.17 & 2.08 & 0.00 & 0.00 & 2.08 & 2.08 & 0.00 \\
\hline 3 & 95.83 & 94.79 & 95.83 & 95.83 & 1.04 & 1.04 & 0.00 & 0.00 & 3.13 & 4.17 & 4.17 & 4.17 \\
\hline 4 & 95.83 & 98.96 & 97.92 & 100.00 & 2.08 & 0.00 & 2.08 & 0.00 & 2.08 & 1.04 & 0.00 & 0.00 \\
\hline 5 & 97.92 & 98.96 & 98.96 & 98.96 & 2.08 & 1.04 & 1.04 & 1.04 & 0.00 & 0.00 & 0.00 & 0.00 \\
\hline 6 & 94.79 & 94.79 & 94.79 & 91.67 & 4.17 & 3.13 & 2.08 & 7.29 & 1.04 & 2.08 & 3.13 & 1.04 \\
\hline 7 & 96.88 & 95.83 & 96.88 & 94.79 & 1.04 & 1.04 & 1.04 & 0.00 & 2.08 & 3.13 & 5.21 & 5.21 \\
\hline 8 & 98.96 & 98.96 & 98.96 & 97.92 & 1.04 & 1.04 & 0.00 & 0.00 & 0.00 & 0.00 & 1.04 & 2.08 \\
\hline 9 & 98.96 & 97.92 & 98.96 & 96.88 & 1.04 & 2.08 & 1.04 & 2.08 & 0.00 & 0.00 & 0.00 & 1.04 \\
\hline 10 & 97.92 & 94.79 & 93.75 & 92.71 & 1.04 & 3.13 & 2.08 & 3.13 & 1.04 & 4.17 & 4.17 & 4.17 \\
\hline 11 & 96.88 & 95.83 & 93.75 & 90.63 & 1.04 & 3.13 & 4.17 & 5.21 & 2.08 & 1.04 & 2.08 & 4.17 \\
\hline 12 & 96.88 & 97.92 & 98.96 & 97.92 & 3.13 & 2.08 & 1.04 & 2.08 & 0.00 & 0.00 & 0.00 & 0.00 \\
\hline average & s96.97 & 96.59 & 96.78 & 96.12 & 1.99 & 1.99 & 1.52 & 1.89 & 1.04 & 1.61 & 1.99 & 1.99 \\
\hline
\end{tabular}




\section{Switch OL-LL math $400-450$ ms window}

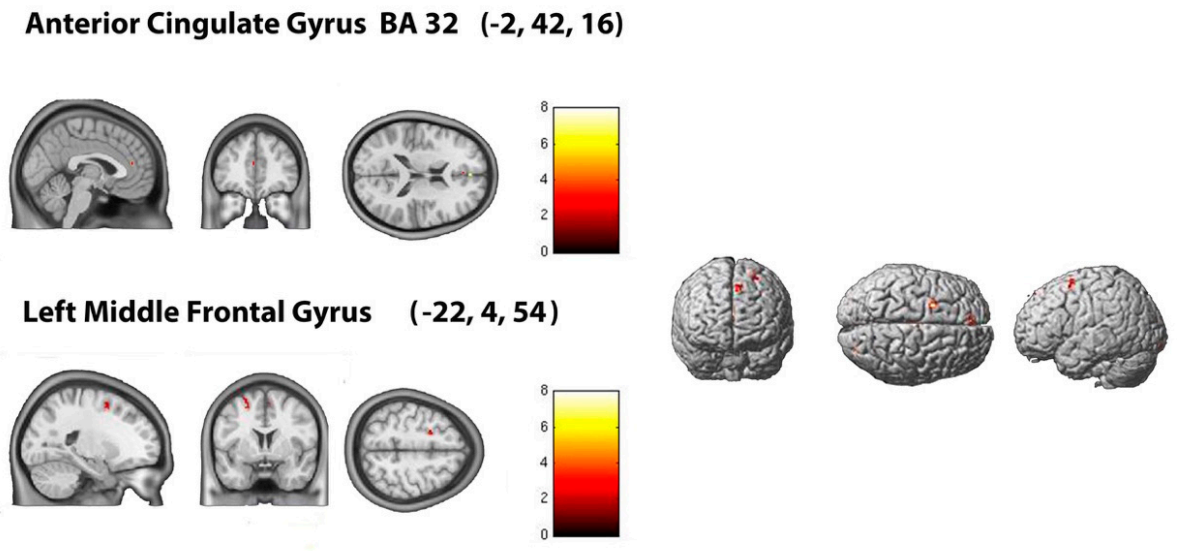

\section{Switch OL-LL ${ }^{\text {math }}$ 450-500 ms window}

\section{Left Inferior Frontal Gyrus $\quad(-54,32,26)$}
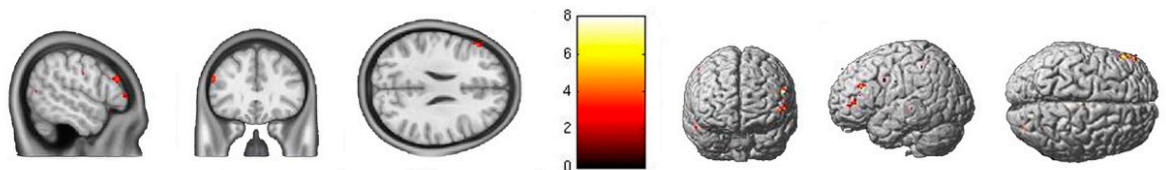

Figure 3. Source analyses revealed main switch effects around $400 \mathrm{~ms}$ in the left hemisphere. The first time-window (400-450 ms) showed the effect in the anterior cingulate gyrus and left middle frontal gyrus. In the second time-window, the effects were similar to those in the previous time-window in the left inferior frontal gyrus.

Table 4. Main effects in the two different time windows (400-450 ms and 450-500 ms) showing the regions where the effect of the switch was located, their coordinates and their respective statistical values ( $\mathrm{T}, \mathrm{Z0}$ and $p$-value).

\begin{tabular}{|c|c|c|c|c|c|}
\hline Time & Brain Region & $\begin{array}{l}\text { Peak MNI Coordinates } \\
\qquad(x, y, z)\end{array}$ & T-Value & $\mathrm{Z}_{0}$-Value & $p$-Value \\
\hline \multirow[t]{2}{*}{$400-450 \mathrm{~ms}$} & $\begin{array}{c}\text { BA } 32 \text { (Anterior Cingulate } \\
\text { Gyrus) }\end{array}$ & $-2,42,16$ & 3.98 & 3.42 & 0.000 \\
\hline & Left Middle Frontal Gyrus & $-22,4,54$ & 3.70 & 3.29 & 0.000 \\
\hline $450-500 \mathrm{~ms}$ & $\begin{array}{l}\text { BA } 9 \text { (Dorsolateral } \\
\text { Prefrontal Cortex) }\end{array}$ & $-54,32,26$ & 3.79 & 3.29 & 0.000 \\
\hline
\end{tabular}




\section{Left Frontal}
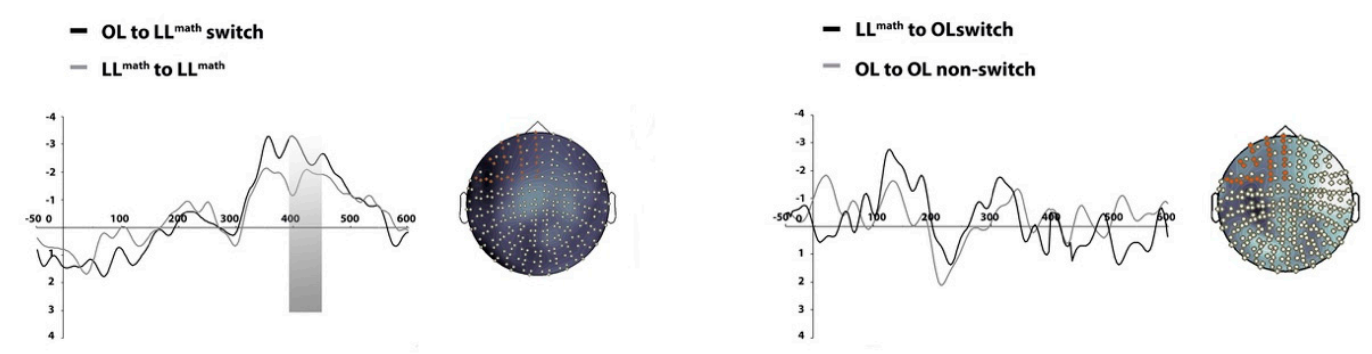

Left Temporal
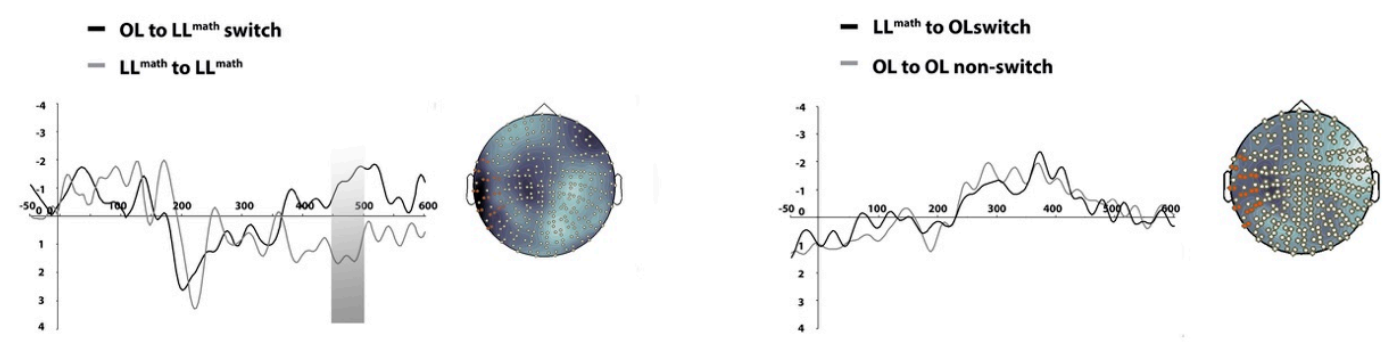

Figure 4. Event related fields (ERF) showing the asymmetry in the switch comparing the OL-LLmath (left part of the figure) versus the LL ${ }^{\text {math }}$-OL switch (right part of the figure). The OL-LL ${ }^{\text {math }}$ direction showed the asymmetry in the switch in two different time windows (400-450 ms and 450-500 ms). In the top of the image the switch effect was found in the left-frontal cluster in the 400-450 ms time window. In the bottom of the image the effect was found in the left temporal cluster for the $450-500 \mathrm{~ms}$ time window.

\section{Conclusions}

In the present study, the unexplored relative dominance between the two codes for math has been investigated during the performance of a code-switching task. Results show that asymmetric switch costs occur when switching between $L^{\text {math }}$ and OL in perfectly balanced bilinguals. This asymmetry is similar to other switch cost asymmetries reported in general language between the first and second languages (L1 and L2) in unbalanced bilinguals (Alvarez et al. 2003; Chauncey et al. 2008; Costa and Santesteban 2004; Duñabeitia et al. 2010; Macizo et al. 2012; Meuter and Allport 1999; Moreno et al. 2002; Palmer et al. 2010; Proverbio et al. 2004). The transition from the non-dominant to the dominant code (OL to LL ${ }^{\text {math }}$ ) implies a larger negativity (a bigger switch cost) at the N400 latency. This switch cost does not depend on the relative proficiency between L1 and L2 but on the LL ${ }^{\text {math }}$ and OL relative proficiency.

Arithmetic memory networks depend on early learning (Salillas and Wicha 2012). Balanced bilinguals have mathematical concepts that are accessed more efficiently in the language in which they learned simple arithmetic. However, also the most basic numerical representation has showed linguistic traces, inherited from early learning (Salillas and Carreiras 2014). When exposure to number words is associated with quantity during early learning, number representations might be shaped by that particular language. The present data crucially extends these conclusions, highlighting the importance of early learning to lexical representations of number words. The bilingual number word system is unbalanced and can cohabit with more balanced representations for non-numerical words in fluent bilinguals. This experiment was designed to explore the dominance of the linguistic codes for math (whether they are LL ${ }^{\text {math }}$ dependent or not). Participants were balanced bilinguals who have learned math in one of their two languages). Results show an asymmetric switch cost in the codes for math, the switch cost occurs in the OL to LL math direction. 
Taken together these results support the predictions formulated in this work. First, we have demonstrated that the switch costs between the two codes for math are asymmetrical. Based on the significant differences found on the ERF analyses, we have shown that the LL ${ }^{\text {math }}$ modulates these asymmetries; such effects are consistent in both behavioral and neuroimaging data as the two techniques show the same results; these switches seem to follow a similar mechanism that language switching and, according to some authors, might trigger general cognitive control mechanisms (Abutalebi et al. 2012; Craik and Bialystok 2006; Dijkstra and Van Heuven 1998; Garbin et al. 2010; Green 1998).

In sum, arithmetic memory networks depend on early learning (Salillas and Wicha 2012). Balanced bilinguals have mathematical concepts that are accessed more efficiently in the language in which they learned simple arithmetic. However also, the most basic numerical representation has showed linguistic traces, inherited from early learning (Salillas and Carreiras 2014). When exposure to number words is associated with quantity during early learning, number representations might be shaped by that particular language. The present data crucially extends these questions and highlights the importance of early learning to lexical representations of number words. The bilingual number word system is unbalanced and can cohabit with more balanced representations for non-numerical words in fluent bilinguals.

This experiment also addressed the neurophysiological effects of the switch cost between the two codes for math and investigated the anatomical basis of these costs. We contrasted the switch versus the non-switch conditions in both the LL ${ }^{\text {math }}$ and OL in a lexical decision task. We found an asymmetry in the switch costs being the OL-LL ${ }^{\text {math }}$ switch direction the one showing the asymmetry. Additionally, the source estimation analyses helped to estimate the brain regions behind this switch and localized it in the left hemisphere, more concretely in frontal and temporal regions. These results are in accordance with previous studies observing the neuroanatomical bases of language switches for language and locate the regions of the switch in frontal regions, more concretely in anterior cingulate gyrus (BA 32), left middle frontal gyrus and DLPFC, which agrees with previous studies locating the sources of the switch in frontal regions (Abutalebi and Green 2007; Hernandez et al. 2001; Hernandez et al. 2000; Rodriguez-Fornells et al. 2005; Wang et al. 2007; Blanco-Elorrieta and Pylkkänen 2016). These locations coincide with the location of general task switching mechanisms in frontal areas of the brain (Craik and Bialystok 2006; Garbin et al. 2010; Abutalebi et al. 2012). The anterior cingulate cortex has been related to attention and comprehension (Carter et al. 1999; Frith et al. 1991; Hikosaka and Isoda 2010) and the left middle frontal gyrus and DLPFC have been reportedly involved in inhibition (Abutalebi and Green 2007), which consequently matches the idea of having the same switch mechanism for both LLmath/OL codes and L1/L2 codes. In conclusion, the control mechanisms applied to numerical lexicons seem of similar nature to those applied to general language, as shown in paradigms using non-numerical words, in the sense that they are sensitive to different baseline activations as reflected by the asymmetry of the switch costs. Therefore, while two different dominance patterns would be at work for numerical and non-numerical words, similar control mechanisms could be acting in both domains.

For math, it seems as the dominant language will always be the one in which numerical knowledge was first acquired. As predicted, the pattern of dominance for math is determined by $L L^{\text {math }}$ even though shared control mechanisms are used.

Funding: This research was supported by a Basque government grant PRE_992 from the Department of Education, Policy, and Culture and by the Castile and León Regional Government and FEDER (ref. VA009P17).

Conflicts of Interest: The author declares no conflict of interest. The funding sponsors had no role in the design of the study; in the collection, analyses, or interpretation of the data; in the writing of the manuscript, or in the decision to publish the results. 


\section{References}

Abutalebi, Jubin. 2008. Neural Aspects of Second Language Representation and Language Control. Acta Psychologica 128: 466-78. [CrossRef] [PubMed]

Abutalebi, Jubin, and David Green. 2007. Bilingual Language Production: The Neurocognition of Language Representation and Control. Journal of Neurolinguistics 20: 242-75. [CrossRef]

Abutalebi, Jubin, Jean Marie Annoni, Ivan Zimine, Alan J. Pegna, Mohamed L. Seghier, Hannelore Lee-Jahnke, François Lazeyras, Stefano F. Cappa, and Asaid Khateb. 2008. Language Control and Lexical Competition in Bilinguals: An Event-Related FMRI Study. Cerebral Cortex 18: 1496-505. [CrossRef] [PubMed]

Abutalebi, Jubin, Pasquale Anthony Della Rosa, David W. Green, Mireia Hernandez, Paola Scifo, Roland Keim, Stefano F. Cappa, and Albert Costa. 2012. Bilingualism Tunes the Anterior Cingulate Cortex for Conflict Monitoring. Cerebral Cortex 22: 2076-86. [CrossRef] [PubMed]

Alvarez, Ruben P., Phillip J. Holcomb, and Jonathan Grainger. 2003. Accessing Word Meaning in Two Languages: An Event-Related Brain Potential Study of Beginning Bilinguals. Brain and Language 87: 290-304. [CrossRef]

Ansari, Daniel. 2008. Effects of Development and Enculturation on Number Representation in the Brain. Nature Reviews Neuroscience 9: 278-91. [CrossRef]

Bernardo, Allan B. I. 2001. Asymmetric Activation of Number Codes in Bilinguals: Further Evidence for the Encoding Complex Model of Number Processing. Memory and Cognition 29: 968-76. [CrossRef]

Bhatia, Tej K., and William C. Ritchie. 2012. Handbook of Bilingualism and Multilingualism. Hoboken: Blackwell Publishing, Ltd. [CrossRef]

Bialystok, Ellen, and Barry Miller. 1999. The Problem of Age in Second-Language Acquisition: Influences from Language, Structure, and Task. Bilingualism: Language and Cognition 2: 127-45. [CrossRef]

Bialystok, Ellen, Fergus I. M. Craik, and Gigi Luk. 2012. Bilingualism: Consequences for Mind and Brain. Trends in Cognitive Sciences 16: 240-50. [CrossRef]

Blanco-Elorrieta, Esti, and Liina Pylkkänen. 2016. Bilingual Language Control in Perception versus Action: MEG Reveals Comprehension Control Mechanisms in Anterior Cingulate Cortex and Domain-General Control of Production in Dorsolateral Prefrontal Cortex. Journal of Neuroscience 36: 290-301. [CrossRef]

Bosch, Laura, and Núria Sebastián-Gallés. 2003. Simultaneous Bilingualism and the Perception of a Language-Specific Vowel Contrast in the First Year of Life. Language and Speech 46: 217-43. [CrossRef] [PubMed]

Calabria, Marco, Mireia Hernández, Francesca Martina Branzi, and Albert Costa. 2012. Qualitative Differences between Bilingual Language Control and Executive Control: Evidence from Task-Switching. Frontiers in Psychology 3: 399. [CrossRef] [PubMed]

Campbell, Jamie I. D. 1994. Architectures for Numerical Cognition. Cognition 53: 1-44. [CrossRef]

Campbell, Jamie I. D. 2005. Asymmetrical Language Switching Costs in Chinese-English Bilinguals' Number Naming and Simple Arithmetic. Bilingualism: Language and Cognition 8: 85-91. [CrossRef]

Campbell, Jamie I. D., and James M. Clark. 1988. An Encoding-Complex View of Cognitive Number Processing: Comment on McCloskey, Sokol, and Goodman (1986). Journal of Experimental Psychology: General 117: $204-14$. [CrossRef]

Campbell, Jamie I. D., and Lynette J. Epp. 2004. An Encoding-Complex Approach to Numerical Cognition in Chinese-English Bilinguals. Canadian Journal of Experimental Psychology/Revue Canadienne de Psychologie Expérimentale 58: 229-44. [CrossRef]

Cappelletti, Marinella, Brian Butterworth, and Michael Kopelman. 2001. Spared Numerical Abilities in a Case of Semantic Dementia. Neuropsychologia 39: 1224-39. [CrossRef]

Carey, S. 2001. Cognitive Foundations of Arithmetic: Evolution and Ontogenisis. Mind E Language 16: 37-55. [CrossRef]

Carey, S. 2004. Bootstraping and the Origin of Concepts. Doedalus Wonter 133: 59-68. [CrossRef]

Carter, Cameron S., Matthew M. Botvinick, and Jonathan D. Cohen. 1999. The Contribution of the Anterior Cingulate Cortex to Executive Processes in Cognition. Reviews in the Neurosciences 10: 49-57. [CrossRef]

Centeno, Jose G., and Loraine K. Obler. 2001. Principles of Bilingualism. In Neuropsychology and the Hispanic Patient: A Clinical Handbook. Abingdon: Taylor \& Francis Online, pp. 75-86. 
Chauncey, Krysta, Jonathan Grainger, and Phillip J. Holcomb. 2008. Code-Switching Effects in Bilingual Word Recognition: A Masked Priming Study with Event-Related Potentials. Brain and Language 105: 161-74. [CrossRef] [PubMed]

Chee, Michael W. L., Edsel W. L. Tan, and Thorsten Thiel. 1999. Mandarin and English Single Word Processing Studied with Functional Magnetic Resonance Imaging. The Journal of Neuroscience: The Official Journal of the Society for Neuroscience 19: 3050-56. [CrossRef]

Chee, Michael W L, Nicholas Hon, Hwee Ling Lee, and Chun Siong Soon. 2001. Relative Language Proficiency Modulates BOLD Signal Change When Bilinguals Perform Semantic Judgments. NeuroImage 13: 1155-63. [CrossRef] [PubMed]

Chee, Michael W L, Chun Siong Soon, and Hwee Ling Lee. 2003. Common and Segregated Neuronal Networks for Different Languages Revealed Using Functional Magnetic Resonance Adaptation. Journal of Cognitive Neuroscience 15: 85-97. [CrossRef] [PubMed]

Christoffels, Ingrid K., Christine Firk, and Niels O. Schiller. 2007. Bilingual Language Control: An Event-Related Brain Potential Study. Brain Research 1147: 192-208. [CrossRef] [PubMed]

Clarkson, Philip C., and Peter Galbraith. 1992. Bilingualism and Mathematics Learning: Another Perspective. Journal for Research in Mathematics Education 23: 34-44. [CrossRef]

Cohen Kadosh, Roi, Kathrin Cohen Kadosh, David E. J. Linden, Wim Gevers, Andrea Berger, and Avishai Henik. 2007. The Brain Locus of Interaction between Number and Size: A Combined Functional Magnetic Resonance Imaging and Event-Related Potential Study. Journal of Cognitive Neuroscience 19: 957-70. [CrossRef] [PubMed]

Cohen Kadosh, Roi, Jan Lammertyn, and Véronique Izard. 2008. Are Numbers Special? An Overview of Chronometric, Neuroimaging, Developmental and Comparative Studies of Magnitude Representation. Progress in Neurobiology 84: 132-47. [CrossRef] [PubMed]

Costa, Albert, and Mikel Santesteban. 2004. Lexical Access in Bilingual Speech Production: Evidence from Language Switching in Highly Proficient Bilinguals and L2 Learners. Journal of Memory and Language 50: 491-511. [CrossRef]

Craik, Fergus I. M., and Ellen Bialystok. 2006. Cognition through the Lifespan: Mechanisms of Change. Trends in Cognitive Sciences 10: 131-38. [CrossRef] [PubMed]

Crinion, Jenny, Robert Turner, Alice Grogan, Takashi Hanakawa, Uta Noppeney, Joseph T. Devlin, Toshihiko Aso, Shinichi Urayama, Hidenao Fukuyama, K. Stockton, and et al. 2006. Language Control in the Bilingual Brain. Science 312: 1537-40. [CrossRef] [PubMed]

Crystal, David. 1996. The Cambridge Encyclopedia of the English Language. Cambridge: Cambridge University Press. [CrossRef]

Damian, Markus F. 2004. Asymmetries in the Processing of Arabic Digits and Number Words. Memory E Cognition 32: 164-71. [CrossRef]

De Bleser, Ria, Patrick Dupont, Jenny Postler, Guy Bormans, Dirk Speelman, Luc Mortelmans, and Mark Debrock. 2003. The Organisation of the Bilingual Lexicon: A PET Study. Journal of Neurolinguistics 16: 439-56. [CrossRef]

De Houver, Annick. 2009. No Early Bilingual Acquisition. In Handbook of Bilingualism. Hoboken: John Wiley \& Sons, Inc.

Dehaene, Stanislas. 1997. The Number Sense. New York: Oxford University Press.

Dehaene, Stanislas, and Laurent Cohen. 1995. Towards an Anatomical and Functional Model of Number Processing. Mathematical Cognition 1: 83-120.

Dehaene, Stanislas, and Laurent Cohen. 1997. Cerebral Pathways for Calculation: Double Dissociation between Rote Verbal and Quantitative Knowledge of Arithmetic. Cortex 33: 219-50. [CrossRef]

Dehaene, Stanislas, Elizabeth Spelke, Philippe Pinel, Ruxandra Stanescu, and Sanna Tsivkin. 1999. Sources of Mathematical Thinking: Behavioral and Brain Imaging Evidence. Science 284: 970-74. [CrossRef] [PubMed]

Dehaene, Stanislas, Manuela Piazza, Philippe Pinel, and Laurent Cohen. 2003. Three Parietal Circuits for Number Processing. Cognitive Neuropsychology 20: 487-506. [CrossRef] [PubMed]

DeKeyser, Robert M. 2005. What Makes Learning Second-Language Grammar Difficult? A Review of Issues. Language Learning 55: 1-25. [CrossRef]

DeKeyser, Robert M., and Jenifer Larson-Hall. 2005. What Does the Critical Period Really Mean. In Handbook of Bilingualism: Psycholinguistic Approaches. New York: Oxford University Press, pp. 88-108.

Delazer, M., and Th Benke. 1997. Arithmetic Facts without Meaning. Cortex 33: 697-710. [CrossRef] 
Delazer, Margarete, Anja Ischebeck, Frank Domahs, Laura Zamarian, Florian Koppelstaetter, Christian Siedentopf, Liane Kaufmann, Thomas Benke, and Stephan Felber. 2005. Learning by Strategies and Learning by Drill-Evidence from an FMRI Study. NeuroImage 25: 838-49. [CrossRef]

Dijkstra, Ton, and Walter J.B. Van Heuven. 1998. "The BIA Model and Bilingual Word Recognition.". Localist Connectionist Approaches to Human Cognition, 189-225. [CrossRef]

Duñabeitia, Jon Andoni, Maria Dimitropoulou, Oxel Uribe-Etxebarria, Itziar Laka, and Manuel Carreiras. 2010. Electrophysiological Correlates of the Masked Translation Priming Effect with Highly Proficient Simultaneous Bilinguals. Brain Research 1359: 142-54. [CrossRef] [PubMed]

Feigenson, Lisa, Stanislas Dehaene, and Elizabeth Spelke. 2004. Core Systems of Number. Trends in Cognitive Sciences 8: 307-14. [CrossRef] [PubMed]

Flege, James Emil, Murray J. Munro, and Ian R. A. Mackay. 1995. Effects of Age of Second-Language Learning on the Production of English Consonants. Speech Communication 16: 1-26. [CrossRef]

Flege, James Emil, Ian R. A. Mackay, and Thorsten Piske. 2002. Assessing Bilingual Dominance. Applied Psycholinguistics 23: 567-98. [CrossRef]

Frenck-Mestre, Cheryl, and Jyotsna Vaid. 1993. Activation of Number Facts in Bilinguals. Memory \& Cognition 21: 809-18. [CrossRef]

Frith, Chris. D., Karl. J Friston, Peter. F. Liddle, and Richard. S. J. Frackowiak. 1991. A PET Study of Word Finding. Neuropsychologia 29: 1137-48. [CrossRef]

Gandour, Jackson, Yunxia Tong, Thomas Talavage, Donald Wong, Mario Dzemidzic, Yisheng Xu, Xiaojian Li, and Mark Lowe. 2007. Neural Basis of First and Second Language Processing of Sentence-Level Linguistic Prosody. Human Brain Mapping 28: 94-108. [CrossRef]

Garbin, Gabrielle, Ana Sanjuan, Cristina Forn, Juan Carlos Bustamante, Aina Rodríguez-Pujadas, Vicente Belloch, Mireia Hernández, Albert Costa, and César Ávila. 2010. Bridging Language and Attention: Brain Basis of the Impact of Bilingualism on Cognitive Control. NeuroImage 53: 1272-78. [CrossRef]

García-Pentón, Lorna, Alejandro Pérez Fernández, Yasser Iturria-Medina, Margaret Gillon-Dowens, and Manuel Carreiras. 2014. Anatomical Connectivity Changes in the Bilingual Brain. NeuroImage 84: 495-504. [CrossRef]

Geary, David C., Pierre Cormier, Judith P. Goggin, Patricia Estrada, and Melanie C. E. Lunn. 1993. Mental Arithmetic: A Componential Analysis of Speed-of-Processing across Monolingual, Weak Bilingual, and Strong Bilingual Adults. International Journal of Psychology 28: 185-201. [CrossRef]

Gelman, Rochel, and Brian Butterworth. 2005. Number and Language: How Are They Related? Trends in Cognitive Sciences 9: 6-10. [CrossRef] [PubMed]

Gelman, Rochel, and Charles R. Gallistel. 1979. The Child's Understanding of Number. Cambridge: Harvard University Press, vol. 8. [CrossRef]

Gilmore, Camilla K., Shannon E. McCarthy, and Elizabeth Spelke. 2010. Non-Symbolic Arithmetic Abilities and Mathematics Achievement in the First Year of Formal Schooling. Cognition 115: 394-406. [CrossRef] [PubMed]

Gordon, Peter. 2004. Numerical Cognition without Words: Evidence from Amazonia. Science 306: 496-99. [CrossRef] [PubMed]

Grabner, Roland H., Henrik Saalbach, and Doris Eckstein. 2012. Language-Switching Costs in Bilingual Mathematics Learning. Mind, Brain, and Education 6: 147-55. [CrossRef]

Gramfort, Alexandre, Martin Luessi, Eric Larson, Denis A. Engemann, Daniel Strohmeier, Christian Brodbeck, Lauri Parkkonen, and Matti S. Hämäläinen. 2014. MNE Software for Processing MEG and EEG Data. NeuroImage 86: 446-60. [CrossRef]

Green, David W. 1998. Mental Control of the Bilingual Lexico-Semantic System. Bilingualism: Language and Cognition 1: 67. [CrossRef]

Grosjean, François. 2010. Bilingual. Life and Reality. Sociolinguistic Studies. Cambridge: Harvard University Press, vol. 6. [CrossRef]

Halberda, Justin, Michèle M. M. Mazzocco, and Lisa Feigenson. 2008. Individual Differences in Non-Verbal Number Acuity Correlate with Maths Achievement. Nature 455: 665-68. [CrossRef]

Hamers, Josiane F., and Michel Blanc. 2000. Bilinguality and Bilingualism. Cambridge: Cambridge University Press. 
Han, Xiao, Jorge Jovicich, David Salat, Andre van der Kouwe, Brian Quinn, Silvester Czanner, Evelina Busa, Jenni Pacheco, Marilyn Albert, Ronald Killiany, and et al. 2006. Reliability of MRI-Derived Measurements of Human Cerebral Cortical Thickness: The Effects of Field Strength, Scanner Upgrade and Manufacturer. NeuroImage 32: 180-94. [CrossRef]

Hazan, Valerie L., and Georges Boulakia. 1993. Perception and Production of a Voicing Contrast by French-English Bilinguals. Language and Speech 36: 17-38. [CrossRef]

Hernandez, Arturo E. 2013. The Bilingual Brain. Oxford: Oxford University Press.

Hernandez, Arturo E., Antigona Martinez, and Kathryn Kohnert. 2000. In Search of the Language Switch: An FMRI Study of Picture Naming in Spanish-English Bilinguals. Brain and Language 73: 421-31. [CrossRef] [PubMed]

Hernandez, Arturo E., Mirella Dapretto, John Mazziotta, and Susan Bookheimer. 2001. Language Switching and Language Representation in Spanish-English Bilinguals: An FMRI Study. NeuroImage 14: 510-20. [CrossRef] [PubMed]

Hikosaka, Okihide, and Masaki Isoda. 2010. Switching from Automatic to Controlled Behavior: Cortico-Basal Ganglia Mechanisms. Trends in Cognitive Sciences 14: 154-61. [CrossRef] [PubMed]

Hodent, Celia, Peter Bryant, and Olivier Houde. 2005. Language-Specific Effects on Number Computation in Toddlers. Developmental Science 8: 420-23. [CrossRef] [PubMed]

Holloway, Ian D., and Daniel Ansari. 2008. Domain-Specific and Domain-General Changes in Children's Development of Number Comparison. Developmental Science 11: 644-49. [CrossRef]

Jackson, Georgina M., Rachel Swainson, Ross Cunnington, and Stephen R. Jackson. 2001. ERP Correlates of Executive Control during Repeated Language Switching. Bilingualism: Language and Cognition 4: 169-78. [CrossRef]

Jackson, Georgina M., Rachel Swainson, Annie Mullin, Ross Cunnington, and Stephen R. Jackson. 2004. ERP Correlates of a Receptive Language-Switching Task. Quarterly Journal of Experimental Psychology Section A: Human Experimental Psychology 57: 223-40. [CrossRef]

Johnson, Jacqueline S., and Elissa L. Newport. 1989. Critical Period Effects in Second Language Learning: The Influence of Maturational State on the Acquisition of English as a Second Language. Cognitive Psychology 21: 60-99. [CrossRef]

Kaplan, Edith, Harold Goodglass, and Sandra Weintraub. 1983. Boston Naming Test. Philadelphia: Lea \& Febiger. [CrossRef]

Kim, Karl HS, Norman R. Relkin, Kyoung-Min Lee, and Joy Hirsch. 1997. Distinct Cortical Areas Associated with Native and Second Languages. Nature 388: 171-74. [CrossRef]

Kolers, Paul A. 1968. Bilingualism and Information Processing. Scientific American 18: 78-86. [CrossRef]

Kroll, Judith F., Paola E. Dussias, Cari A. Bogulski, and Jorge R. Valdes Kroff. 2012. 7 Juggling Two Languages in One Mind: What Bilinguals Tell Us About Language Processing and Its Consequences for Cognition. Psychology of Learning and Motivation-Advances in Research and Theory 56: 229.

Lemer, Cathy, Stanislas Dehaene, Elizabeth Spelke, and Laurent Cohen. 2003. Approximate Quantities and Exact Number Words: Dissociable Systems. Neuropsychologia 41: 1942-58. [CrossRef]

Lenneberg, Eric H. 1967. Biological Foundations of Language. Neurology 17: 1219. [CrossRef]

Long, Michael H. 1990. Maturational Constraints on Language Development. Studies in Second Language Acquisition 12: 251-85. [CrossRef]

Macizo, Pedro, Teresa Bajo, and Daniela Paolieri. 2012. Language Switching and Language Competition. Second Language Research 28: 131-49. [CrossRef]

Macnamara, John. 1967. The Bilingual's Linguistic Performance-A Psychological Overview. Journal of Social Issues 23: 58-77. [CrossRef]

Marsh, Linda Gutiérrez, and Ruth Hipple Maki. 1976. Efficiency of Arithmetic Operations in Bilinguals as a Function of Language. Memory \& Cognition 4: 459-64. [CrossRef]

Martinez-Lincoln, Amanda, Christina Cortinas, and Nicole Y. Y. Wicha. 2015. Arithmetic Memory Networks Established in Childhood Are Changed by Experience in Adulthood. Neuroscience Letters 584: 325-30. [CrossRef] [PubMed]

Meuter, Renata F. I., and Alan Allport. 1999. Bilingual Language Switching in Naming: Asymmetrical Costs of Language Selection. Journal of Memory and Language 40: 25-40. [CrossRef] 
Morales, Romelia V., Valerie J. Shute, and James W. Pellegrino. 1985. Developmental Differences in Understanding and Solving Simple Mathematics Word Problems. Cognition and Instruction 2: 41-57. [CrossRef]

Moreno, Eva M., Kara D. Federmeier, and Marta Kutas. 2002. Switching Languages, Switching Palabras (Words): An Electrophysiological Study of Code Switching. Brain and Language 80: 188-207. [CrossRef] [PubMed]

Moschkovich, Judit. 2007. Using Two Languages When Learning Mathematics. Educational Studies in Mathematics 64: 121-44. [CrossRef]

Moyer, Robert S., and Thomas K. Landauer. 1967. Time Required for Judgements of Numerical Inequality. Nature 215: 1519-20. [CrossRef] [PubMed]

Nieder, Andreas, and Stanislas Dehaene. 2009. Representation of Number in the Brain. Annual Review of Neuroscience 32: 185-208. [CrossRef] [PubMed]

Noël, Marie-Pascale, and Xavier Seron. 1997. On the Existence of Intermediate Representations in Numerical Processing. Journal of Experimental Psychology: Learning, Memory, and Cognition 23: 697-720. [CrossRef]

Palmer, Shekeila D., Johanna C. van Hooff, and Jelena Havelka. 2010. Language Representation and Processing in Fluent Bilinguals: Electrophysiological Evidence for Asymmetric Mapping in Bilingual Memory. Neuropsychologia 48: 1426-37. [CrossRef] [PubMed]

Perani, Daniela, Eraldo Paulesu, Nuria Sebastian Galles, Emmanuel Dupoux, Stanislas Dehaene, Valentino Bettinardi, Stefane F. Cappa, Ferruccio Fazio, and Jacques Mehler. 1998. The Bilingual Brain. Proficiency and Age of Acquisition of the Second Language. Brain 121: 1841-52. [CrossRef] [PubMed]

Perani, Daniela, Jubin Abutalebi, Eraldo Paulesu, Simona Brambati, Paola Scifo, Stefano F. Cappa, and Ferruccio Fazio. 2003. The Role of Age of Acquisition and Language Usage in Early, High-Proficient Bilinguals: An FMRI Study during Verbal Fluency. Human Brain Mapping 19: 170-82. [CrossRef] [PubMed]

Piazza, Manuela. 2011. Neurocognitive Start-Up Tools for Symbolic Number Representations. Space, Time and Number in the Brain 1: 267-85. [CrossRef]

Piazza, Manuela, Pierre Pica, Véronique Izard, Elizabeth Spelke, and Stanislas Dehaene. 2013. Education Enhances the Acuity of the Nonverbal Approximate Number System. Psychological Science 24: 1037-43. [CrossRef]

Pica, Pierre, Cathy Lemer, Véronique Izard, and Stanislas Dehaene. 2004. Exact and Approximate Arithmetic in an Amazonian Indigene Group. Materials and Method. Science 306: 1-16. [CrossRef] [PubMed]

Pinker, Steven. 1994. The Language Instinct. How the Mind Creates Language. Harper Collins: Harper Collins Publishing.

Proverbio, Alice Mado, Giuliana Leoni, and Alberto Zani. 2004. Language Switching Mechanisms in Simultaneous Interpreters: An ERP Study. Neuropsychologia 42: 1636-56. [CrossRef] [PubMed]

Reuter, Martin, Nicholas J Schmansky, H Diana Rosas, and Bruce Fischl. 2012. Within-Subject Template Estimation for Unbiased Longitudinal Image Analysis. NeuroImage 61: 1402-18. [CrossRef] [PubMed]

Rodriguez-Fornells, Antoni, Michael Rotte, Hans-Jochen Heinze, Tömme Nösselt, and Thomas F. Münte. 2002. Brain Potential and Functional MRI Evidence for How to Handle Two Languages with One Brain. Nature 415: 1026-29. [CrossRef] [PubMed]

Rodriguez-Fornells, Antoni, Arie van der Lugt, Michael Rotte, Belinda Britti, Hans-Jochen Heinze, and Thomas F. Münte. 2005. Second Language Interferes with Word Production in Fluent Bilinguals: Brain Potential and Functional Imaging Evidence. Journal of Cognitive Neuroscience 17: 422-33. [CrossRef]

Rodriguez-Fornells, Antoni, Ruth De Diego Balaguer, and Thomas F. Münte. 2006. Executive Control in Bilingual Language Processing. Language Learning 56: 133-90. [CrossRef]

Salillas, Elena, and Manuel Carreiras. 2014. Core Number Representations Are Shaped by Language. Cortex 52: 1-11. [CrossRef]

Salillas, Elena, and Alejandro Martínez. 2018. Linguistic Traces in Core Numerical Knowledge: An Approach From Bilingualism. In Language and Culture in Mathematical Cognition. New York: Academic Press, pp. 173-96. [CrossRef]

Salillas, Elena, and Nicole Y. Y. Wicha. 2012. Early Learning Shapes the Memory Networks for Arithmetic: Evidence from Brain Potentials in Bilinguals. Psychological Science 23: 745-55. [CrossRef]

Salillas, Elena, Paulo Barraza, and Manuel Carreiras. 2015. Oscillatory Brain Activity Reveals Linguistic Prints in the Quantity Code. PLoS ONE 10: e0121434. [CrossRef]

Seron, Xavier, and Marie-Pascale Noel. 1995. Transcoding Numbers from the Arabic Code to the Verbal One or Vice Versa: How Many Routes. Mathematical Cognition 1: 5-243. 
Spelke, Elizabeth. 2000. Core Knowledge of Objects. American Psychologist 55 (November). American Psychologist 55: 1233-43. [CrossRef] [PubMed]

Spelke, Elizabeth, and Sanna Tsivkin. 2001. Language and Number: A Bilingual Training Study. Cognition 78: 45-88. [CrossRef]

Swainson, Rachel, Ross Cunnington, Georgina M. Jackson, Chris Rorden, Andrew M. Peters, Peter G. Morris, and Steven R. Jackson. 2003. Cognitive Control Mechanisms Revealed by ERP and FMRI: Evidence from Repeated Task-Switching. Journal of Cognitive Neuroscience 15: 785-99. [CrossRef] [PubMed]

Tadel, François, Sylvain Baillet, John C. Mosher, Dimitrios Pantazis, and Richard M Leahy. 2011. Brainstorm: A User-Friendly Application for MEG/EEG Analysis. Computational Intelligence and Neuroscience 2011: 879716. [CrossRef] [PubMed]

Taulu, Samu, Juha Simola, and Matti Kajola. 2005. Applications of the Signal Space Separation Method. IEEE Transactions on Signal Processing 53: 3359-72. [CrossRef]

Temple, Elise, and Michael I. Posner. 1998. Brain Mechanisms of Quantity Are Similar in 5-Year-Old Children and Adults. Proceedings of the National Academy of Sciences of the United States of America 95: 7836-41. [CrossRef] [PubMed]

Vaid, Jyotsna, and Ramdas Menon. 2000. Correlates of Bilinguals' Preferred Language for Mental Computations. Spanish Applied Linguistics 4: 325-42.

Valdes, Guadalupe, Heather Brookes, and Christina Chavez. 2003. Bilinguals and Bilingualism. Lawrence Erlbaum. Available online: http://repository.hsrc.ac.za/handle/20.500.11910/8186 (accessed on 16 August 2019).

Van Heuven, Walter J. B., Herbert Schriefers, Ton Dijkstra, and Peter Hagoort. 2008. Language Conflict in the Bilingual Brain. Cerebral Cortex 18: 2706-16. [CrossRef]

Venkatraman, Vinod, Soon Chun Siong, Michael W. L. Chee, and Daniel Ansari. 2006. Effect of Language Switching on Arithmetic: A Bilingual FMRI Study. Journal of Cognitive Neuroscience 18: 64-74. [CrossRef]

Verhoef, Kim, Ardi Roelofs, and Dorothee J Chwilla. 2009. Role of Inhibition in Language Switching: Evidence from Event-Related Brain Potentials in Overt Picture Naming. Cognition 110: 84-99. [CrossRef]

Wang, Yapeng, Gui Xue, Chuansheng Chen, Feng Xue, and Qi Dong. 2007. Neural Bases of Asymmetric Language Switching in Second-Language Learners: An ER-FMRI Study. NeuroImage 35: 862-70. [CrossRef] [PubMed]

Weber-Fox, Christine M., and Helen J. Neville. 1996. Maturational Constraints on Functional Specializations for Language Processing: ERP and Behavioral Evidence in Bilingual Speakers. Journal of Cognitive Neuroscience 8: 231-56. [CrossRef] [PubMed]

Whalen, John, Charles R. Gallistel, and Rochel Gelman. 1999. Nonverbal Counting in Humans: The Psychophysics of Number Representation. Psychological Science 10: 130-37. [CrossRef]

Wynn, Karen. 1990. Children's Understanding of Counting. Cognition 36: 155-93. [CrossRef]

Xu, Daming, and Pack Ling Tan. 1997. Foundations of Bilingual Education and Bilingualism (2nd Edition). International Journal of Bilingualism 1. [CrossRef]

Yetkin, Oguz, F. Zerrin Yetkin, Victor M Haughton, and Robert W Cox. 1996. Use of Functional MR to Map Language in Multilingual Volunteers. American Journal of Neuroradiology 17: 473-77. [PubMed]

Zhang, Jiajie, and Donald A. Norman. 1995. A Representational Analysis of Numeration Systems. Cognition 57: 271-95. [CrossRef]

(C) 2019 by the author. Licensee MDPI, Basel, Switzerland. This article is an open access article distributed under the terms and conditions of the Creative Commons Attribution (CC BY) license (http://creativecommons.org/licenses/by/4.0/). 